\title{
Insect Derived Lauric Acid as Promising Alternative Strategy to Antibiotics in the Antimicrobial Resistance Scenario
}

\author{
Luca Borrelli*, Lorena Varriale*, Ludovico Dipineto, Antonino Pace, Lucia F. Menna and \\ Alessandro Fioretti
}

Department of Veterinary Medicine and Animal Productions, Università degli Studi di Napoli Federico II, Naples, Italy

\section{OPEN ACCESS}

Edited by:

Junying Ma,

Chinese Academy of Sciences, China

Reviewed by:

Joshua A. Jackman,

Sungkyunkwan University,

South Korea

Min Yue,

Zhejiang University, China

Nam-Joon Cho,

Nanyang Technological University,

Singapore

*Correspondence:

Luca Borrelli

luca.borrelli@unina.it

Lorena Varriale

lorena.varriale@unina.it

Specialty section:

This article was submitted to Antimicrobials, Resistance

and Chemotherapy,

a section of the journa

Frontiers in Microbiology

Received: 23 October 2020 Accepted: 03 February 2021

Published: 26 February 2021

Citation:

Borrelli L, Varriale L, Dipineto L, Pace A, Menna LF and Fioretti A (2021) Insect Derived Lauric Acid as

Promising Alternative Strategy to Antibiotics in the Antimicrobial

Resistance Scenario.

Front. Microbiol. 12:620798. doi: 10.3389/fmicb.2021.620798
Antibiotic misuse is greatly contributing to an increase in antimicrobial resistance (AMR) in humans and animals. Natural and synthetic alternative strategies are being investigated in human and veterinary medicine, but little attention is paid to the antimicrobial effects of edible lipids, such as medium-chain fatty acids (MCFAs) and monoglycerides. Among MCFAs, lauric acid (LA) and its monoglyceride derivative, glycerol monolaurate (GML), exhibit the strongest antimicrobial activity. Coconut and palm kernel oils are considered the main sources of LA. On the other hand, some edible insects (e.g., Hermetia illucens) are gaining interest as novel feed ingredients, due to the high amount of LA they contain as well as their numerous bioactive components, which provide many additional benefits to animal health. Although the beneficial effect of both MCFAs and LA is gradually being recognized, their high content within insects and, consequently, their possible role as antimicrobials, has not been well-reported. This mini review focuses on the anti-infective effects of the insect-derived MCFAs $L A$ and its derivatives. We emphasize the potential of insect lipids, compared to the other vegetable sources, in the current global scenario where a sustainable and circular economy is required. Finally, we critically discuss the use and the benefits of edible insects such as favorable options as feed and food from the perspective of animal and human nutrition.

Keywords: post-antibiotic epoch, Hermetia illucens, lauric acid, MCFAs, novel antimicrobial lipids

\section{TACKLING THE RISE OF ANTIMICROBIAL RESISTANCE. ANY LIPIDIC ALTERNATIVES?}

A New York Times headline from 1945 reads "Penicillin's finder assays its future; Sir Alexander Fleming observed that improved dosage method is needed to extend use." Despite this early warning, today, antimicrobial resistance (AMR) represents a global-scale public threat, and the world is now on the cusp of a "post-antibiotic era." The research community is investing in various drug discovery strategies to develop new antimicrobial drugs, as conventional drug therapies are becoming increasingly ineffective and limited (Farha and Brown, 2019; Schultz et al., 2020). Every year, 700,000 patients die worldwide due to AMR, but the number could easily and dramatically 
reach 10 million by 2050 (Ghosh et al., 2019). Antibiotic abuse both in humans and animals has greatly contributed to an increase in AMR and has also caused the accumulation of these compounds in the environment by selecting resistant microorganisms and turning the environment into an enormous reservoir for AMR genes (Roca et al., 2015). Moreover, antibiotics misuse in animal production and the EU ban on their use in feed (Regulation EC/1831/2003) has led to an increase in the incidence of livestock disease and economic damage (Dabbou et al., 2020).

To date, numerous natural and synthetic alternative strategies are being investigated such as antibodies, bacteriophages, antimicrobial peptides, and alteration of the gut microbiota, predatory bacteria, or fecal transplant therapy (Kadouri et al., 2013; Aroniadis and Brandt, 2014; Mandal et al., 2014; Mahlapuu et al., 2016; Ghosh et al., 2019; Rello et al., 2019). Antimicrobial lipids, such as medium-chain fatty acids (MCFAs) and monoglycerides could also be a suitable alternative to antibiotics. MCFAs are originally an important component of the innate immune system in mammalian breast milk, skin, and mucosa and also induce host defense peptides expression in humans and animals (Zhou et al., 2019). Among MCFAs, lauric acid (LA) (Figure 1A) and its monoglyceride derivative, monolaurin (glycerol monolaurate, GML) (Figure 1B), exhibit the strongest antimicrobial activity. They can modulate intestinal health by regulating the level of IL- 6 and TNF- $\alpha$ (Dabbou et al., 2020) and, not least, they are Generally Recognized As Safe (GRAS) by the United States Food and Drug Administration (Yoon et al., 2018). Their ability to destabilize the bacterial cell membrane makes them promising candidates among novel antimicrobials because these bacteria are also unlikely to acquire resistance to these compounds (Petschow et al., 1996; Schlievert and Peterson, 2012; Jackman et al., 2020).

Although the beneficial effect of MCFAs and LA is gradually being recognized, their content within insects has not been well-reported. Recently, insects have been receiving considerable attention as novel alternative feed ingredients because of their excellent nutritional properties and potential effects on animal health. They contain bioactive components, such as LA, antimicrobial peptides (defensins, cecropins, attacins, lebocins, lysozime proline-rich peptides, gloverins, and moricins) and the valuable biopolymer chitin, part of the exoskeletons of arthropods and chitosan, produced commercially by deacetylation of chitin which has antimicrobial,
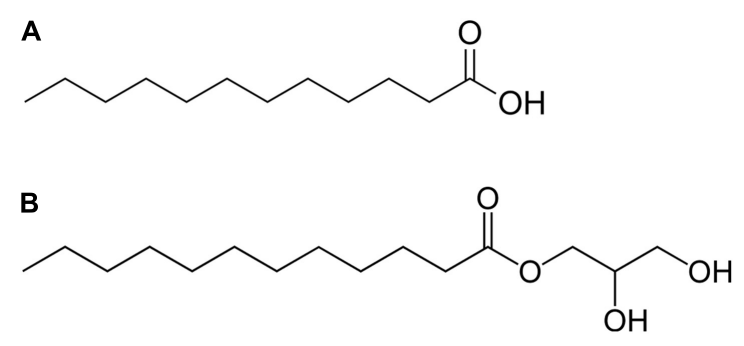

FIGURE 1 | Chemical structure of lauric acid (A) and glycerol monolaurate (B). anti-tumor and immune-boosting properties (Sogari et al., 2019; da Silva Lucas et al., 2020; Moretta et al., 2020; Smets et al., 2020).

Among edible insects, Hermetia illucens is one of the main sources of LA (Spranghers et al., 2018). Thus, it may represent a good candidate given the growing market demand for edible insects as a new source of food, and also considering the need to find new strategies for antimicrobial resistance. Therefore, based on the studies presented so far, the perspectives for future applications of insect lipids might also be considered in human nutrition.

\section{ANTIMICROBIAL EFFECT OF THE LAURIC ACID AND MONOLAURIN}

A recent overview reports the emerging antimicrobial properties of fatty acids (FAs) and their relation to virulence and quorum sensing (QS), such as diffusible signal factors (DSFs), acyl-homoserine lactones, and autoinducer-2 systems. The suppression of the expression of QS-regulated genes, especially those related to virulence (e.g., synthesis of toxins, fimbriae, hyphae, etc.) and other non-QS targets (proteins involved in efflux pumps, oxidative stress, and ergosterol synthesis) make FAs a new paradigm to cope with drug-resistant bacteria (Kumar et al., 2020). Of these, medium-chain fatty acids (MCFAs) and their monoglycerides have a broad spectrum of microbicidal activity against a wide range of pathogens both in vitro and in vivo, including multidrug-resistant bacteria, enveloped viruses, algae, fungi, and protozoa (Bergsson et al., 2001; Hilmarsson et al., 2007; Yoon et al., 2018; Zhou et al., 2019; Heriyati et al., 2020; Welch et al., 2020).

In the 1970s, Kabara's group carried out a wide-ranging assessment of the antibacterial activities of FAs and contributed to define the modern-day field of antimicrobial lipids from a chemical viewpoint (Yoon et al., 2018). LA and GML represent the strongest antimicrobial agents in mammalian milk, they are also found in other natural sources such as coconut oil and are often used as nutritional supplements (Lieberman et al., 2006; Dayrit, 2015; Kim and Rhee, 2016).

Due to their amphipathic properties, MCFAs exhibit an antimicrobial activity through a membrane-lytic behavior causing increased cell permeability and cell lysis. In addition, MCFAs disrupt the electron transport chain either by binding to electron carriers or interfering with oxidative phosphorylation, which are vital processes for energy production in bacterial cells. Furthermore, MCFAs can directly inhibit membrane enzymes such as glucosyltransferase and also target other membrane-associated proteins (Yoon et al., 2018). In some in silico studies, LA has been proposed as a natural antibacterial agent via inhibiting the MurA enzyme, which is involved in bacterial cell wall biosynthesis (Heriyati et al., 2020). Galbraith and Miller (1973a,b) reported that the activity of LA was decreased by $\mathrm{Mg}^{2+}$ and $\mathrm{Ca}^{2+}$ ions and increased by lower $\mathrm{pH}$, suggesting that the uptake of LA is modulated by physico-chemical properties of both the acid and the bacterial surface. MCFAs 
and monoglycerides mainly work in the micellar state. Monoglycerides form micelles at lower concentrations than MCFAs, which helps to clarify why monoglycerides are often more biologically potent than FAs (Jackman et al., 2020). Overall, the esterification of a fatty acid to its corresponding monoglyceride derivative enhances the antibacterial effect (Yoon et al., 2018).

Kumar et al. (2020) showed that LA inhibits the swarming motility of $P$. mirabilis in a dose-dependent manner and, at higher levels, acts on Clostridium difficile cell membranes and adhesins. LA can inhibit hemolysin expression, extracellular polysaccharides (EPS) and biofilm production through RsbA (a histidine-containing phosphotransmitter of two-component signaling system) dependent pathway.

Additionally, GML may almost completely kill the vegetative cells and spores of aerobic and anaerobic bacteria (Schlievert et al., 2018; Yang et al., 2018). GML also inhibits the production of staphylococcal toxic shock toxin-1 effectively and the expression of virulence factors including protein A, alpha-hemolysin, $\beta$-lactamase, and the induction of vancomycin resistance in Enterococcus faecalis by interfering with signal transduction (Projan et al., 1994; Ruzin and Novick, 2000).

MCFAs and monoglycerides have been suggested as natural compounds for the control of various foodborne pathogens (Kim and Rhee, 2016; Dhakal and Aldrich, 2020). Hovorková et al. (2018) discovered that the bactericidal effect of MCFAs did not exert inhibitory effects against gut commensal bacteria.

MCFAs and their monoglycerides have emerged as promising additives for replacing in-feed antibiotics and promoting sustainable animal-food production, enhancing growth performance and animal welfare (Jackman et al., 2020). Apart from the direct effects on intestinal microbiota, MCFAs could have positive effects on gut health, modulated by the degree of esterification. MCFAs can improve the intestinal morphology and function, through their beneficial effects on crypt cell renewal (Spranghers et al., 2018) and have also an immunomodulatory activity (Zhang et al., 2016). Indeed, new evidence points out that incubation of lauric acid, also found in human sebum, enhanced the innate immune defense of human sebocytes by upregulating the gene and protein expression of $\beta$-defensin-2, one of the most represented antimicrobial peptides detected in the skin (Zhou et al., 2019). In addition, LA has even been indicated as a natural antibiotic against some dermal infections, such as acne, with no toxic effect on human sebocytes (Nakatsuji et al., 2009).

As natural molecules, fatty acids have great potential and their combination with antimicrobials could reduce multidrugresistant bacteria (Kumar et al., 2020).

\section{HERMETIA ILLUCENS AS ONE OF THE MAIN SOURCES OF ANTIMICROBIAL LIPIDS}

H. illucens (HI), a Diptera known as the black soldier fly (Sheppard et al., 2002) is a native of tropical, subtropical, and warm temperate zones of America. It is now widespread in tropical and warmer temperate regions between about $45^{\circ} \mathrm{N}$ and $40^{\circ} \mathrm{S}$ (Makkar et al., 2014). HI has been proposed since the $1990 \mathrm{~s}$ as an efficient way to dispose of organic waste by converting it into a protein-rich and fat-rich biomass suitable for various purposes, including animal feeding, biodiesel, oil, and chitin production (van Huis et al., 2013).

For nutritional purposes, insects' fat was extracted from a limited number of species, i.e., HI, Tenebrio molitor, Zophobas morio, and Bombyx mori. Among these, $\mathrm{HI}$ has the highest amount of LA (up to 60\%) (Spranghers et al., 2017), while in T. molitor it is less than 0.5\% (van Huis et al., 2013; Gasco et al., 2019). HI oil also consists of various monoglycerides, diglycerides, and triglyceride, showing a very similar fatty acid profile and quality compared to that of coconut and palm kernel oil (Ushakova et al., 2016; Muller et al., 2017; Spranghers et al., 2017). LA concentration and synthesis may, however, undergo small variations according to the substrate used, to the shift from lipogenesis to glycogenesis related to the development stage, to the extraction methods, and the killing method and storage (Alifian et al., 2019; Caligiani et al., 2019; Rabani et al., 2019; Ewald et al., 2020; Kierończyk et al., 2020).

The high fat content of the prepupae could limit their use as a feed ingredient. Thus, it could be interesting to partially extract the fat from the prepupal meal and use a sufficient amount of LA in the feed adding value to it, while the extracted part could be suitable for other purposes, such as the production of biofuel (Spranghers et al., 2017).

To reduce the costs for lipid extraction, the major challenges are large-scale production and legal frameworks to allow the use of insects as ingredients for food and feed. So far, insect lipids are allowed in feeding all animal species, but PAPs (processed animal proteins) are only permitted in aquaculture and the possibility of extending the authorization of their use to poultry and swine feed is still pending (Sogari et al., 2019).

$\mathrm{HI}$ is not considered a disease vector, since the adult fly is not attracted to human habitats or foods and the eggs are never laid on decaying organic material. Furthermore, the prepupae process organic waste very quickly and empty their digestive tract, limiting bacterial proliferation (van Huis et al., 2013; Makkar et al., 2014; Muller et al., 2017). Moreover, the larvae modify the microflora of manure, potentially reducing harmful bacteria such as Escherichia coli 0157:H7 and Salmonella enterica (Makkar et al., 2014).

$\mathrm{HI}$ is characterized by an immune system in which cell-mediated and humoral innate mechanisms work jointly. Hemolymph cells are involved in cellular immune responses, while phenoloxidase, antimicrobial peptides (AMPs), and proteins belong to humoral innate response (Zdybicka-Barabas et al., 2017). HI contains chitin which exhibits antimicrobial properties (Borrelli et al., 2017).

Up until recently, research has examined different strategies to take advantage of $\mathrm{HI}$ immunity. As reported, the modulation of the substrate where the larvae are fed could induce the expression of different proteins and specific immunity gene proteins with a different spectrum of antimicrobial activity (Zdybicka-Barabas et al., 2017; Vogel et al., 2018). 
TABLE 1 | Antimicrobial effect of insect-derived LA and GML in in vivo animal studies.

\begin{tabular}{|c|c|c|c|}
\hline Elicitors & Animal species & Key findings & References \\
\hline HI meal & Weaned piglets & 2 log fold reduction of D-Streptococci & Spranghers et al., 2018 \\
\hline HI meal & Weanling piglets & $\begin{array}{l}\text { Increased number of Lactobacillus and Bifidobacterium, quadratically } \\
\text { decreasing number of E. coli }\end{array}$ & Yu et al., 2020 \\
\hline HI meal & Finishing pigs & $\begin{array}{l}\text { Decreased abundance of Streptococcus spp., increased number of } \\
\text { Lactobacillus, higher concentrations of total SCFA, upregulation of } \\
\text { anti-inflammatory cytokine (IL-10) }\end{array}$ & Yu et al., 2019 \\
\hline HI oil & Growing rabbits & $\begin{array}{l}\text { Significantly lower growth of Yersinia enterocolitica, positive influence on } \\
\text { the cecal microbiota }\end{array}$ & Dabbou et al., 2020 \\
\hline HI meal & Siberian sturgeon & $\begin{array}{l}\text { Positive effect on the gut microbiota composition and intestinal } \\
\text { morphology }\end{array}$ & Józefiak et al., 2019 \\
\hline HI oil & Young turkey & Reduced growth of Enterobacteriaceae, decreasing levels of IL-6 & Sypniewski et al., 2020 \\
\hline
\end{tabular}

\section{ANTIMICROBIAL PROPERTIES OF HERMETIA ILLUCENS LARVAE INCLUSION IN ANIMAL FEEDING}

As natural and edible antimicrobial products, MCFAs have been proposed as alternatives to conventional antibiotic growth promoters in livestock nutrition (Fortuoso et al., 2019; Zhou et al., 2019). In the last few years, the use of insect-based diet as HIL meal and oil in substitution of the conventional feedstuffs has been investigated showing promising findings in terms of nutritive value and low environmental impact, with negligible effects on lipid digestibility, performance parameters, and animal health in the swine, poultry and rabbit industry (Cullere et al., 2016, 2018, 2019a; Dalle Zotte et al., 2018, 2019; Secci et al., 2018; Gariglio et al., 2019; Gasco et al., 2019; Yu et al., 2019, 2020).

To date, data on the antimicrobial effects of insect-based diet in vivo are scarce. All available studies are summarized in Table $\mathbf{1}$.

\section{INSECT-BASED FOOD PERSPECTIVES IN HUMAN NUTRITION}

The nutritional values of available insects differ according to species, effects of diet or substrate, and environmental conditions. However, it is interesting that the value of some insect species in insect products is better than meat. The risk of consuming edible insects for humans compared with consuming other animal products or food protein sources is lesser-known. The EFSA has highlighted a lack of data regarding microbiology, virology, parasitology, and toxicology of edible insects. Currently, there is very limited information on the risks associated with families or species of insects, details of the manufacturing processes and the environmental impact of different farming systems, and there is also a lack of human consumption data (Ferri et al., 2019; van Huis, 2020).

Over recent decades, human nutrition has undergone dramatic changes such as an increased intake of partially hydrogenated oils and trans fatty acids, which may lead to a pro-inflammatory state, associated with obesity, type 2 diabetes, and other epidemic metabolic disorders in western countries (van den Brink et al., 2019).
The insect bioactive peptides and lipids have beneficial effects on human health, such as antioxidant, antimicrobial and antidiabetic properties, angiotensin I converting enzyme (ACE) inhibition activity, effects against inflammation and cancer. Insects can be also used as functional food ingredients (Dutta et al., 2019; da Silva Lucas et al., 2020).

Insect diet might also promote metabolic shifts, including the increased production of microbiota-derived short-chain fatty acids (SCFAs) such as butyrate, acetate, and propionate (Borrelli et al., 2017), exhibiting antibacterial activity against various pathogens (Yang et al., 2018). SCFAs improve mucosal and systemic innate and acquired immune responses to control inflammation during infections and reinforce homeostasis. Butyrate also inhibits histone deacetylase 3 to confer macrophages with non-inflammatory enhanced antimicrobial activity (Shinde et al., 2020).

As possible drawbacks for human nutrition, insect lipid fraction, unlike vegetable oils, is low in poly-unsaturated Fatty Acids (PUFA). As new alternatives to improve insect fats, the modulation of the substrate for the larvae by using fish-offal waste could increase the $n-3$ proportion in Hermetia illucens larvae meal and oil, as well as the direct inclusion of a PUFArich feed ingredient (i.e., linseed) in animal diets, could be a useful strategy to provide healthier meat for human consumption (Cullere et al., 2019b; Caimi et al., 2020). Moreover, MCFAs show low solubility and unpleasant odors that stimulate the release of cholecystokinin and reduce the feed intake of animals. Encapsulation of MCFAs could be a suitable solution to overcome these limits (Zhou et al., 2019).

Due to their nutrient profile, insects could also be a game changer in the race to fight hunger, food insecurity, malnutrition (da Silva Lucas et al., 2020). There are many articles on the antimicrobial effects of GML in vitro and in vivo in animal studies but only three papers highlight in vivo antimicrobial effects in humans (Barker et al., 2019). However, other in vivo human studies and further research is recommended.

\section{CONCLUDING REMARKS}

Antimicrobial resistance (AMR) is an impending public health crisis. As we respond to the COVID-19 pandemic, we 
are seeing what our health systems look like, with limited treatments available to tackle an outbreak. To stem the rise of AMR infections, physicians, veterinarians, and environmental scientists must all remain vigilant and maintain a one health view. This mini review shows how Hermetia illucens (HI) represent a good candidate source of LA with a potential role in the AMR scenario. In particular, HI-derived oil might be useful in protecting against microbial infections, modulating inflammation, healing wounds, and controlling the balance and distribution of bacteria in gut microbiota. The presence of insect-derived LA in animal feed could prevent the use of conventional antibiotics in meat production, limiting the diffusion of microbes harboring AMR genes (Dabbou et al., 2020).

If whole insects are used as feed, the antimicrobial molecules must remain stable during feed processing and digestion. Thus, these compounds could be purified and identified directly from larval extracts, or it would be possible to characterize in vitro HI immunity-related genes with the aim to discover novel antimicrobials and molecules (De Smet et al., 2018).

The MCFAs composition of HIL oil is very similar and can replace palm kernel or coconut oil, as additives and even pharmaceuticals (Matthäus et al., 2019; Rabani et al., 2019). Both vegetable oils are products of plants from tropical climates, where they are abundant. The impact on the environment is also considerable, as an increase in demand for vegetable oils and biofuels contributes to water waste, tropical deforestation, loss in biodiversity, and habitat fragmentation. For this reason,

\section{REFERENCES}

Alifian, M. D., Sholikin, M. M., Evvyernie, D., and Nahrowi, R. (2019). Potential fatty acid composition of Hermetia illucens oil reared on different substrates. IOP Conf. Ser. Mater. Sci. Eng. 546:062002. doi: 10.1088/1757-899X/546/6/ 062002

Aroniadis, O. C., and Brandt, L. J. (2014). Intestinal microbiota and the efficacy of fecal microbiota transplantation in gastrointestinal disease. Gastroenterol. Hepatol. (N. Y). 10, 230-237.

Barker, L. A., Bakkum, B. W., and Chapman, C. (2019). The clinical use of monolaurin as a dietary supplement: a review of the literature. J. Chiropr. Med. 18, 305-310. doi: 10.1016/j.jcm.2019.02.004

Bergsson, G., Arnfinnsson, J., Steingrimsson, O., and Thormar, H. (2001). In vitro killing of Candida albicans by fatty acids and monoglycerides. Antimicrob. Agents Chemother. 45, 3209-3212. doi: 10.1128/AAC.45.11.3209-3212.2001

Borrelli, L., Coretti, L., Dipineto, L., Bovera, F., Menna, L. F., Chiariotti, L., et al. (2017). Insect-based diet, a promising nutritional source, modulates gut microbiota composition and SCFAs production in laying hens. Sci. Rep. 7:16269. doi: 10.1038/s41598-017-16560-6

Caimi, C., Renna, M., Lussiana, C., Bonaldo, A., Gariglio, M., Meneguz, M., et al. (2020). First insights on black soldier fly (Hermetia illucens L.) larvae meal dietary administration in Siberian sturgeon (Acipenser baerii Brandt) juveniles. Aquaculture 515:734539. doi: 10.1016/j.aquaculture.2019.734539

Caligiani, A., Marseglia, A., Sorci, A., Bonzanini, F., Lolli, V., Maistrello, L., et al. (2019). Influence of the killing method of the black soldier fly on its lipid composition. Food Res. Int. 116, 276-282. doi: 10.1016/j.foodres.2018.08.033

Cullere, M., Schiavone, A., Dabbou, S., Gasco, L., and Dalle Zotte, A. (2019a). Meat quality and sensory traits of finisher broiler chickens fed with black soldier fly (Hermetia Illucens L.) larvae fat as alternative fat source. Animals 9:140. doi: 10.3390/ani9040140

Cullere, M., Tasoniero, G., Giaccone, V., Acuti, G., Marangon, A., and Dalle Zotte, A. (2018). Black soldier fly as dietary protein source for broiler quails: meat palm kernel and coconut oil are currently criticized from an ecological point of view (Wang and Shelomi, 2017; Matthäus et al., 2019; Verheyen et al., 2020; Kierończyk et al., 2020). Therefore, in a vision of the circular economy, it would be possible to manage, reduce, and efficiently use organic waste for HIL rearing as a sustainable source of nutrients (according to the $4 \mathrm{R}$ of the EU Parliament Directive no. 2008/98 and the other Directive 94/62/EC).

The Hippocratic concept that "we are what we eat" is present in all cultures and it represents one of the biggest barriers to the consumption of insects in food neofobic western societies, which consider entomophagy to be disgusting (van Huis et al., 2013). The scientific community and all stakeholders must now make efforts to promote insects as a source of bioactive peptides and lipids and to prevent the next global threat of antimicrobial resistance as well as metabolic disorders.

If "we are what we eat," but obesity, diabetes, cancer, and antimicrobial resistance are constantly increasing in western society, why not eat insects?

\section{AUTHOR CONTRIBUTIONS}

LB and LV conducted the literature searches, conceptualized, and wrote the manuscript. LD and AP critically revised the manuscript. LM and AF read, revised, and concurred with the final version of the review. All authors have made an intellectual contribution to the work and approved the submitted version.

proximate composition, fatty acid and amino acid profile, oxidative status and sensory traits. Animal 12, 640-647. doi: 10.1017/S1751731117001860

Cullere, M., Tasoniero, G., Giaccone, V., Miotti-Scapin, R., Claeys, E., De Smet, S., et al. (2016). Black soldier fly as dietary protein source for broiler quails: apparent digestibility, excreta microbial load, feed choice, performance, carcass and meat traits. Animal 10, 1923-1930. doi: 10.1017/S1751731116001270

Cullere, M., Woods, M. J., van Emmenes, L., Pieterse, E., Hoffman, L. C., and DalleZotte, A. (2019b). Hermetia illucens larvae reared on different substrates in broiler quail diets: effect on physicochemical and sensory quality of the quail meat. Animals (Basel) 9:525. doi: 10.3390/ani9080525

da Silva Lucas, A. J., de Oliveira, L. M., da Rocha, M., and Prentice, C. (2020). Edible insects: an alternative of nutritional, functional and bioactive compounds. Food Chem. 311:126022. doi: 10.1016/j.foodchem.2019.126022

Dabbou, S., Ferrocino, I., Gasco, L., Schiavone, A., Trocino, A., Xiccato, G., et al. (2020). Antimicrobial effects of black soldier fly and yellow mealworm fats and their impact on gut microbiota of growing rabbits. Animals 10:1292. doi: 10.3390/ani10081292

Dalle Zotte, A., Cullere, M., Martins, C., Alves, S. P., Freire, J. P. B., Falcão-ECunha, L., et al. (2018). Incorporation of black soldier fly (Hermetia Illucens L.) larvae fat or extruded linseed in diets of growing rabbits and their effects on meat quality traits including detailed fatty acid composition. Meat Sci. 146, 50-58. doi: 10.1016/j.meatsci.2018.08.002

Dalle Zotte, A., Singh, Y., Michiels, J., and Cullere, M. (2019). Black soldier fly (Hermetia Illucens) as dietary source for laying quails: live performance, and egg physico-chemical quality, sensory profile and storage stability. Animals (Basel) 9:115. doi: 10.3390/ani9030115

Dayrit, F. M. (2015). The properties of lauric acid and their significance in coconut oil. J. Am. Oil Chem. Soc. 92, 1-15. doi: 10.1007/s11746-014-2562-7

De Smet, J., Wynants, E., Cos, P., and Campenhout, L. (2018). Microbial community dynamics during rearing of black soldier fly larvae (Hermetia illucens) and impact on exploitation potential. Appl. Environ. Microbiol. 1:84. doi: 10.1128/AEM.02722-17 
Dhakal, J., and Aldrich, C. G. (2020). Use of medium chain fatty acids to mitigate Salmonella typhimurium (ATCC 14028) on dry pet food kibbles. J. Food Prot. 83, 1505-1511. doi: 10.4315/JFP-20-114

Dutta, P., Sahu, R. K., Dey, T., Lahkar, M. D., Manna, P., and Kalita, J. (2019). Beneficial role of insect-derived bioactive components against inflammation and its associated complications (colitis and arthritis) and cancer. Chem. Biol. Interact. 313:1088243. doi: 10.1016/j.cbi.2019.108824

Ewald, N., Vidakovic, A., Langeland, M., Kiessling, A., Sampels, S., and Lalander, C. (2020). Fatty acid composition of black soldier fly larvae (Hermetia illucens) possibilities and limitations for modification through diet. Waste Manag. 102, 40-47. doi: 10.1016/j.wasman.2019.10.014

Farha, M. A., and Brown, E. D. (2019). Drug repurposing for antimicrobial discovery. Nat. Microbiol. 4, 565-577. doi: 10.1038/s41564-019-0357-1

Ferri, M., Di Federico, F., Damato, S., Proscia, F., and Grabowski, N. T. (2019). Insects as feed and human food and the public health risk - a review. Berl. Münch. Tierärztl. Wochenschr. 132, 191-218. doi: 10.2376/0005-9366-18064

Fortuoso, B. F., dos Reis, J. H., Gebert, R. R., Barreta, M., Griss, L. G., Casagrande, R. A., et al. (2019). Glycerol monolaurate in the diet of broiler chickens replacing conventional antimicrobials: impact on health, performance and meat quality. Microb. Pathog. 129, 161-167. doi: 10.1016/j.micpath.2019.02.005

Galbraith, H., and Miller, T. B. (1973a). Effect of metal cations and $\mathrm{pH}$ on the antibacterial activity and uptake of long chain fatty acids. J. Appl. Bacteriol. 36, 635-646. doi: 10.1111/j.1365-2672.1973.tb04149.x

Galbraith, H., and Miller, T. B. (1973b). Physicochemical effects of long chain fatty acids on bacterial cells and their protoplasts. J. Appl. Bacteriol. 36, 647-658. doi: 10.1111/j.1365-2672.1973.tb04150.x

Gariglio, M., Dabbou, S., Biasato, I., Capucchio, M. T., Colombino, E., Hernández, F., et al. (2019). Nutritional effects of the dietary inclusion of partially defatted Hermetia illucens larva meal in Muscovy duck. J. Anim. Sci. Biotechnol. 10:37. doi: 10.1186/s40104-019-0344-7

Gasco, L., Dabbou, S., Trocino, A., Xiccato, G., Capucchio, M. T., Biasato, I., et al. (2019). Effect of dietary supplementation with insect fats on growth performance, digestive efficiency and health of rabbits. J. Anim. Sci. Biotechnol. 10:4. doi: 10.1186/s40104-018-0309-2

Ghosh, C., Sarkar, P., Issa, R., and Haldar, J. (2019). Alternatives to conventional antibiotics in the era of antimicrobial resistance. Trends Microbiol. 27, 323-338. doi: 10.1016/j.tim.2018.12.010

Heriyati, Y., Astrid, Y., Shadrina, A. A. N., Wiani, I., Satari, M. H., and Kurnia, D. (2020). Potential fatty acid as antibacterial agent against oral bacteria of Streptococcus mutans and Streptococcus sanguinis from Basil (Ocimum americanum): in vitro and in silico studies. Curr. Drug Discov. Technol. 17, doi: 10.2174/1570163817666200712171652 [Epub ahead of print].

Hilmarsson, H., Traustason, B., Kristmundsdóttir, T., and Thormar, H. (2007). Virucidal activities of medium-and long-chain fatty alcohols and lipids against respiratory syncytial virus and parainfluenza virus type 2: comparison at different pH levels. Arch. Virol. 152, 2225-2236. doi: 10.1007/s00705-0071063-5

Hovorková, P., Laloučková, K., and Skřivanová, E. (2018). Determination of in vitro antibacterial activity of plant oils containing medium-chain fatty acids against gram- positive pathogenic and gut commensal bacteria. Czech. J. Anim. Sci. 63, 119-125. doi: 10.17221/70/2017-CJAS

Jackman, J. A., Boyd, R. D., and Elrod, C. C. (2020). Medium-chain fatty acids and monoglycerides as feed additives for pig production: towards gut health improvement and feed pathogen mitigation. J. Anim. Sci. Biotechnol. 11:44. doi: 10.1186/s40104-020-00446-1

Józefiak, A., Nogales-Mérida, S., Rawski, M., Kierończyk, B., and Mazurkiewicz, J. (2019). Effects of insect diets on the gastrointestinal tract health and growth performance of Siberian sturgeon (Acipenser baerii Brandt, 1869). BMC Vet. Res. 15:348. doi: 10.1186/s12917-019-2070-y

Kadouri, D. E., To, K., Shanks, R. M., and Doi, Y. (2013). Predatory bacteria: a potential ally against multidrug-resistant Gram-negative pathogens. PLoS One 8:e63397. doi: 10.1371/journal.pone.0063397

Kierończyk, B., Sypniewski, J., Rawski, M., Czekała, W., Świạtkiewicz, S., and Józefiak, D. (2020). From waste to sustainable feed material: the effect of Hermetia Illucens oil on the growth performance, nutrient digestibility, and gastrointestinal tract morphometry of broiler chickens. Ann. Anim. Sci. 20, 157-177. doi: 10.2478/aoas-2019-0066
Kim, S. A., and Rhee, M. S. (2016). Highly enhanced bactericidal effects of medium chain fatty acids (caprylic, capric, and lauric acid) combined with edible plant essential oils (carvacrol, eugenol, b-resorcylic acid, trans-cinnamaldehyde, thymol, and vanillin) against Escherichia coli O157:H7. Food Control 60, 447454. doi: 10.1016/j.foodcont.2015.08.022

Kumar, P., Lee, J. H., Beyenal, H., and Lee, J. (2020). Fatty acids as antibiofilm and antivirulence agents. Trends Microbiol. 28, 9753-9768. doi: 10.1016/j.tim.2020. 03.014

Lieberman, S., Enig, M., and Preuss, H. (2006). A review of monolaurin and lauric acid: natural virucidal 348 and bactericidal agents. Altern. Complement.Ther. 12, 310-314. doi: 10.1089/act.2006.12.310

Mahlapuu, M., Håkansson, J., Ringstad, L., and Björn, C. (2016). Antimicrobial peptides: an emerging category of therapeutic agents. Front. Cell. Infect. Microbiol. 6:194. doi: 10.3389/fcimb.2016.00194

Makkar, H. P. S., Tranb, G., Heuzéb, V., and Ankers, P. (2014). State of the art on use of insects as animal feed. Anim. Feed Sci. Technol. 197, 1-33. doi: 10.1016/j.anifeedsci.2014.07.008

Mandal, S. M., Roy, A., Ghosh, A. K., Hazra, T. K., Basak, A., and Franco, O. L. (2014). Challenges and future prospects of antibiotic therapy: from peptides to phages utilization. Front. Pharmacol. 5:105. doi: 10.3389/fphar.2014. 00105

Matthäus, B., Piofczyk, T., Katz, H., and Pudel, F. (2019). Renewable resources from insects: exploitation, properties, and refining of fat obtained by cold-pressing from Hermetia illucens (Black Soldier Fly) larvae. Eur. J. Lipid Sci. Technol. 121:1800376. doi: 10.1002/ejlt.201800376

Moretta, A., Salvia, R., Scieuzo, C., Di Somma, A., Vogel, H., Pucci, P., et al. (2020). A bioinformatic study of antimicrobial peptides identified in the Black Soldier Fly (BSF) Hermetia illucens (Diptera: Stratiomyidae). Sci. Rep. 10:16875. doi: 10.1038/s41598-020-74017-9

Muller, A., Wolf, D., and Gutzeit, H. O. (2017). The black soldier fly, Hermetia illucens - a promising source for sustainable production of proteins, lipids and bioactive substances. Z. Naturforsch. 72, 351-363. doi: 10.1515/znc-2017-0030

Nakatsuji, T., Kao, M. C., Fang, J. Y., Zouboulis, C. C., Zhang, L., Gallo, R. L., et al. (2009). Antimicrobial property of lauric acid against Propionibacterium acnes: its therapeutic potential for inflammatory acne vulgaris. J. Invest. Dermatol. 129, 2480-2488. doi: 10.1038/jid.2009.93

Petschow, B. W., Batema, R. P., and Ford, L. L. (1996). Susceptibility of Helicobacter pylori to bactericidal properties of medium-chain monoglycerides and free fatty acids. Antimicrob. Agents Chemother. 40, 302-306. doi: 10.1128/AAC.40.2.302

Projan, S. J., Brown-Skrobot, S., Schlievert, P. M., Vandenesch, F., and Novick, R. P. (1994). Glycerol monolaurate inhibits the production of $\beta$-lactamase, toxic shock syndrome toxin-1, and other staphylococcal exoproteins by interfering with signal transduction. J. Bacteriol. 176, 4204-4209.

Rabani, V., Cheatsazan, H., and Davani, S. (2019). Proteomics and lipidomics of Black Soldier Fly (diptera: stratiomyidae) and blow fly (diptera: calliphoridae) larvae. J. Insect Sci. 19:29.

Rello, J., Parisella, F. R., and Perez, A. (2019). Alternatives to antibiotics in an era of difficult-to-treat resistance: new insights. Expert. Rev. Clin. Pharmacol. 12, 635-642. doi: 10.1080/17512433.2019.1619454

Roca, I., Akova, M., Baquero, F., Carlet, J., Cavaleri, M., Coenen, S., et al. (2015). The global threat of antimicrobial resistance: science for intervention. New Microbes New Infect. 6, 22-29.

Ruzin, A., and Novick, R. P. (2000). Equivalence of lauric acid and glycerol monolaurate as inhibitors of signal transduction in Staphylococcus aureus. J. Bacteriol. 182, 2668-2671.

Schlievert, P. M., Kilgore, S. H., Kaus, G. M., Ho, T. D., and Ellermeier, C. D. (2018). Glycerol monolaurate (GML) and a nonaqueous five-percent GML gel kill Bacillus and Clostridium spores. mSphere 3:e00597-18.

Schlievert, P. M., and Peterson, M. L. (2012). Glycerol monolaurate antibacterial activity in broth and biofilm cultures. PLoS One 7:e40350. doi: 10.1371/journal. pone. 0040350

Schultz, F., Anywar, G., Tang, H., Chassagne, F., Lyles, J. T., Garbe, L. A., et al. (2020). Targeting ESKAPE pathogens with anti-infective medicinal plants from the Greater Mpigi region in Uganda. Sci. Rep. 10:11935.

Secci, G., Moniello, G., Gasco, L., Bovera, F., and Parisi, G. (2018). Barbary partridge meat quality as affected by Hermetia illucens and Tenebrio molitor larva meals in feeds. Food Res. Int. 112, 291-298. 
Sheppard, D. C., Tomberlin, J. K., Joyce, J. A., Kiser, B. C., and Sumner, S. M. (2002). Rearing methods for the black soldier fly (Diptera: Stratiomyidae). J. Med. Entomol. 39, 695-698.

Shinde, T., Hansbro, P.M., Sohal, S.S., Dingle, P., Eri, R., and Stanley, R. (2020). Microbiota Modulating Nutritional Approaches to Countering the Effects of Viral Respiratory Infections Including SARS-CoV-2 through Promoting Metabolic and Immune Fitness with Probiotics and Plant Bioactives. Microorganisms 8, 921. doi: 10.3390/microorganisms8060921

Smets, R., Verbinnen, B., Van De Voorde, I., Aerts, G., Claes, J., and Van Der Borght, M. (2020). Sequential extraction and characterisation of lipids, proteins, and chitin from black soldier fly (Hermetia illucens) larvae, prepupae, and pupae. Waste Biomass Valor. 11, 6455-6466.

Sogari, G., Amato, M., Biasato, I., Chiesa, S., and Gasco, L. (2019). The Potential Role of Insects as Feed: A Multi-Perspective Review. Animals (Basel) 9:119. doi: 10.3390/ani9040119

Spranghers, T., Michiels, J., Vrancx, J., Ovyn, A., Eeckhout, M., De Clercq, P., et al. (2018). Gut antimicrobial effects and nutritional value of black soldier fly (Hermetia illucens L.) prepupae for weaned piglets. Anim. Feed Sci. Technol. 235, 33-42. doi: 10.1016/j.anifeedsci.2017.08.012

Spranghers, T., Ottoboni, M., Klootwijk, C., Ovyn, A., Deboosere, S., De Meulenaer, B., et al. (2017). Nutritional composition of black soldier fly (Hermetia illucens) prepupae reared on different organic waste substrates. $J$. Sci. Food Agric. 97, 2594-2600.

Sypniewski, J., Kierończyk, B., Benzertiha, A., Mikołajczak, Z., PruszyńskaOszmałek, E., Kołodziejski, P., et al. (2020). Replacement of soybean oil by Hermetia illucens fat in turkey nutrition: effect on performance, digestibility, microbial community, immune and physiological status and final product quality. Br. Poult. Sci. 61, 294-302. doi: 10.1080/00071668.2020.1716302

Ushakova, N. A., Brodskii, E. S., Kovalenko, A. A, Bastrakov, A. I., Kozlova, A. A., and Pavlov, D. S. (2016). Characteristics of lipid fractions of larvae of the black soldier fly Hermetia illucens. Dokl. Biochem. Biophys. 468, 209-212. doi: 10.1134/S1607672916030145

van den Brink, W., van Bilsen, J., Salic, K., Hoevenaars, F. P. M., Verschuren, L., Kleemann, R., et al. (2019). Current and Future Nutritional Strategies to Modulate Inflammatory Dynamics in Metabolic Disorders. Front. Nutr. 6, 129. doi: 10.3389/fnut.2019.00129

van Huis, A., Van Itterbeeck, J., Klunder, H., Mertens, E., Halloran, A., Muir, G., and Vantomme, P. (2013). Edible Insects - Future Prospects for Food and Feed Security. FAO Forestry Paper 171.

van Huis, A., (2020). Nutrition and health of edible insects. Curr. Opin. Clin. Nutr. Metab. Care. 23, 228-231. doi: 10.1097/MCO.0000000000000641

Verheyen, G. R., Theunis, M., Vreysen, S., Naessens, T., Noyens, I., Ooms, T., et al. (2020). Glycine-acyl surfactants prepared from black soldier fly fat, coconut oil and palm kernel oil. Curr. Green Chem. 7, 239 . doi: 10.2174/ 2213346107999200424084626

Vogel, H., Müller, A., Heckel, D., Gutzeit, H., and Vilcinskas, A. (2018). Nutritional immunology: diversification and diet-dependent expression of antimicrobial peptides in the black soldier fly Hermetia illucens. Dev. Comp. Immunol. 78,141-148. doi: 10.1016/j.dci.2017.09.008

Wang, Y.-S., and Shelomi, M. (2017). Review of black soldier fly (Hermetia illucens) as animal feed and human food. Foods 6:91. doi: 10.3390/foods610 0091

Welch, J. L., Xiang, J., Okeoma, C. M., Schlievert, P. M., and Stapleton, J. T. (2020). Glycerol monolaurate, an analogue to a factor secreted by Lactobacillus, is virucidal against enveloped viruses, including HIV-1. mBio. 11:e00686-20. doi: $10.1128 / \mathrm{mBio} .00686-20$

Yang, H. T., Chen, J. W., Rathod, J., Jiang, Y. Z., Tsai, P. J., Hung, Y. P., et al. (2018). Lauric acid is an inhibitor of Clostriudium difficile growth in vitro and reduces inflammation in a mouse infection model. Front. Microbiol. 8:2635. doi: 10.3389/fmicb.2017.02635

Yoon, B. K., Jackman, J. A., Valle-González, E., and Cho, N. J. (2018). Antibacterial free fatty acids and monoglycerides: biological activities, experimental testing, and therapeutic applications. Int. J.Mol. Sci. 19:1114. doi: 10.3390/ijms1904 1114

Yu, M., Li, Z., Chen, W., Rong, T., Wang, G., and Ma, X. (2019). Hermetia illucens larvae as a potential dietary protein source altered the microbiota and modulated mucosal immune status in the colon of finishing pigs. J. Anim. Sci. Biotechnol. 10:50. doi: 10.1186/s40104-019-0358-1

Yu, M., Li, Z., Chen, W., Wang, G., Rong, T., Liu, Z., et al. (2020). Hermetia illucens larvae as a Fishmeal replacement alters intestinal specific bacterial populations and immune homeostasis in weanling piglets. J. Anim. Sci. 98:skz395. doi: $10.1093 /$ jas/skz395

Zdybicka-Barabas, A., Bulak, P., Polakowski, C., Bieganowski, A., Waoeko, A., and Cytryn ska, M. (2017). Immune response in the larvae of the black soldier fly Hermetia illucens. Invertebrate Surviv. J. 14, 9-17.

Zhang, M. S., Sandouk, A., and Houtman, J. C. (2016). Glycerol monolaurate (GML) inhibits human $\mathrm{T}$ cell signaling and function by disrupting lipid dynamics. Sci Rep. 6:30225.

Zhou, Z., Huang, J., Hao, H., Wei, H., Zhou, Y., and Peng, J. (2019). Applications of new functions for inducing host defense peptides and synergy sterilization of medium chain fatty acids in substituting in-feed antibiotics. J. Funct. Foods, 52,348-59. doi: 10.1016/j.jff.2018.11.028

Conflict of Interest: The authors declare that the research was conducted in the absence of any commercial or financial relationships that could be construed as a potential conflict of interest.

Copyright (c) 2021 Borrelli, Varriale, Dipineto, Pace, Menna and Fioretti. This is an open-access article distributed under the terms of the Creative Commons Attribution License (CC BY). The use, distribution or reproduction in other forums is permitted, provided the original author(s) and the copyright owner(s) are credited and that the original publication in this journal is cited, in accordance with accepted academic practice. No use, distribution or reproduction is permitted which does not comply with these terms. 